\title{
Economic and legal aspects of digital transformation in mining industry
}

\author{
M. Paschke \\ University Hamburg, Hamburg, Germany \\ O. Lebedeva
}

PhD, Associate Professor, Department of Economics, Accounting and Finance, Saint Petersburg Mining University, Saint-Petersburg, Russian Federation

M. Shabalov

PhD, Associate Professor, Department of Economics, Accounting and Finance, Saint Petersburg Mining University, Saint-Petersburg, Russian Federation

D. Ivanova

PhD student, Department of Economics, Accounting and Finance, Saint Petersburg Mining University, Saint-Petersburg, Russian Federation

\begin{abstract}
The article presents the aspects of the industrial digital transformation that currently is taking place in various economic sectors and mining industry is not an exception. Particularly, the authors analyze the development of information technologies in the industry and conduct comparative analysis of digital technologies use in mining with reference to the business sector. The article highlights various features accompanying the digital development of a company, such as the share of employed ICT specialists in a company, the presence of Internet sites, the use of cloud services etc. Apart from economic aspects the article raises a number of social problems that cause the low level of digital development in Russia. In addition, international comparisons are given. Other crucial aspect analyzed in the article is the legal regulation of the process of digital transformation of industry. Its imperfection and need for improvement is justified. Special attention is given to the role of education in the development of the digital technologies and the mining industry as a whole.
\end{abstract}

\section{INTRODUCTION}

In the era of rapid digitalization of economy and society, sustainable development of digital technologies and their successful application in management are the source of comparative competitive advantages at different levels - from countries and sectors of the economy to entities and individuals. For instance, Federation of German Industries estimates the potential of adding extra value due to digital transformation to be around 425 billion Euros by 2025 , while European industry as a whole can get additional 1.25 trillion Euros for the period of 2015-2025 (Bloching et al. 2015). An interest in international comparisons of countries' positions in terms of success in digitalization is expressed in the emergence of a fairly large number of ratings and indexes. Russia's positions in them are neither leading nor lingering. So, for example, in 2017, according to the ICT Development Index 2017, Russia ranked 45th in the world (out of 176), and in 2018 it became one of the 62 leading countries, ranking 32nd in the e-Government Development Index (UN E-Government Survey 2018), and 26th out of 175 in Global Cybersecurity Index (Global Cybersecurity Index, ITU 2018). Judging by maturity indicator, calculated in the Dell Digital Transformation Index, Russia scored 49 
points out of 100 in 2018, along with countries such as Spain, Poland and China (Dell 2019). According to the same rating, $7 \%$ of Russian companies participating in the survey are classified as digital leaders ( $5 \%$ worldwide average), another $19 \%$ are implementing large-scale innovative digital projects, which is slightly lower than the global average of $23 \%$ (Dell 2019).

Both the scientific and business community are actively involved in the study of methodological and applied aspects of the industrial digital transformation (including mining industry). They also exchange their opinions and experience on international scientific platforms about development and implementation of industry-specific digital solutions and creation of the necessary infrastructure. Another discussion those communities have is focused on urgent development issues of the laws governing digitalization at the national and international levels, and the search for acceptable forms of economic cooperation.

\section{LITERATURE REVIEW}

Issues devoted to the relevance of digital technologies in solving production and business tasks of mining companies are widely covered in scientific publications. These issues involve the needs of companies arising from the specific features of mining production, application areas of digital solutions and industry achievements in digital transformation of business (Litvinenko et al. 2019). Recent publications summarize mining's digital demand (Young \& Rogers 2019) and highlight development trends for digital technologies in the sector, as well as scientific interest for them (Barnelwold 2019). In Barnewold (2019), conclusions on current trends in the use of digital technologies in the extractive sector were formulated by the author based on the results of three-steps co-word analysis, including programmed based text-mining algorithms. As a result of 2400 publications of consulting firms and online libraries analysis, the author identified most actual digital trends in industry: automation, big data, internet of things, artificial intelligence and machine learning, and he also detected links between them (Barnelwold 2019). Analyzing the annual reports of the world's largest mining companies by capitalization, other researchers also confirm that "automation" is the most common term, along with "innovations" and "technologies", which reflects the general orientation of mining companies' development priorities in the world (Young \& Rogers 2019).

Numerous scientific publications are devoted to the advantages of the industry technological development based on Internet of things (Gackowiec et al. 2019; Bhuiya 2019, Zhukovskiy et al. 2019a), digital twins (Oracle 2017; Jiewu et al., 2019), predictive capabilities of big data technologies in terms of production safety (Lee et al. 2019). The influence of digital technologies on operational efficiency, sustainable supply chain performance, competitive advantages and value delivery is also investigated (Young \& Rogers 2019; Bag et al., 2019), as well as the role of predictive data mining algorithms, which in conjunction with real options create operational flexibility (Ajak et al. 2018; Fourie 2019). The researchers also pay attention to essential components of big data ecosystem in manufacturing (Cui et al. 2020).

Among widely discussed issues regarding digital technologies is the mutual impact of academia and digitalization process. It is nowadays accepted that contemporary higher education will be relying on digital technologies more and more since students nowadays have deeper understanding of them (Castañeda 2018; Bergdahl et al. 2020, Blaj-Ward 2019). The trend has ingrained in developed countries, where Learning Management Systems (LMS) are essential for any high ranked University administration and education processes. Of course, in other countries LMS are being introduced in Universities with less success, but process is inevitable due to the time costs reduction.

In "What's next for Ed-Tech?" (Selwynn et al. 2020) authors describe and forecast 6 main challenges regarding education development in next decade, naming commercialization of digital learning tools as a main threat to freedom of this process - which is a very vague problem. At the same time, there are a number of end-to-end digital technologies already introduced in education with different levels of efficiency, which are of special interest for researchers, who are trying to understand which digital technologies are in demand in 
educational process and how it is affected by them via various means of direct questioning interviews, polls, queries (Henderson et al. 2017; Bond, 2018; Magana, 2017; Wright, 2014). All these publications are applicable to specific field of mining industry education as well as to any other industry. It is worth noting that visualization of teaching material is far more important in mining - and this problem is being rapidly solved by introduction of augmented, virtual and mixed reality technologies (Abdelrazeq et al. 2019).

Such kind of modern technologies facilitate both a better perception of information and its memorization and integration into the student's existing knowledge system. This contributes to the fact that the student gain knowledge that becomes a "living practice" and get satisfaction from the learning process, which effectiveness increases (Kretschmann et al. 2020).

Despite the impressive number of academic papers, justifying different kinds of advantages of digital technologies application, there is still a gap between the digitalization degree of the extractive sector and other sectors of the economy.

Since some researchers characterize the level of digital transformation of mining industry as low, in comparison with other sectors of the economy (Young \& Rogers 2019; Stepanov 2019), and the reasons underpinning the current status have not been totally investigated yet, the aim of this work is to reveal some economic and legal issues that impede the intensive digital transformation of mining companies in Russia and abroad and to suggest potential mitigation options. The research questions corresponding to the aim of the study are formulated as follows:

1. What is the position of Russian mining companies regarding digital technologies application?

2. Which factors, economic and legal by nature, can be considered as barriers to more successful digital transformation of mining industry?

\section{METHODOLOGY}

The results obtained by the authors are based on application of desk research aimed at collecting and analysis of the relevant industry-oriented academic papers, official statistics and company data, which enabled classification of the key constraints preventing full-scale application of digital technologies in production processes and management of mining companies in Russia. Authors applied elements of benchmarking while carrying out comparative analysis of mining and other industries' achievements in the field of digital transformation. To detect and characterize the challenging legal issues of digitalization, both national and international, the analysis of laws was involved.

The official statistics and materials of analytical overviews, prepared by High School of Economics (HSE) in conjunction with Federal State Statistics Service, as well as reports of companies (KPMG, PwC, Dell Technologies, Accenture) and international organizations (UN, ITU) devoted to mining sector and international comparisons in digitization were used in the research.

\section{RESULTS}

\subsection{Sectoral analysis of digital transformation of Russian business}

To define the relative position of Russian mining companies in application of digital technologies we used domestic sectoral statistics. The analysis allowed us to conclude that in many respects organizations of extractive sector are lagging behind other sectors of the Russian economy. For example, only $39.7 \%$ of mining organizations have websites (as of 2017). For comparison: on average, for all organizations in business sector, the figure is $44 \%$, in telecommunications industry $-67.9 \%$; in manufacturing $-63.8 \%$; in energy supply organizations $47.5 \%$ (HSE 2019). The share of ICT specialists employed in the extractive industry is small only $1.3 \%$ of their total number in the country (for comparison: $14.2 \%$ of ICT specialists are employed in the manufacturing sector) (HSE 2019). In terms of the use of cloud services, the industry is one of the three lagging behind $-17.8 \%$ of mining organizations use cloud services 
(the business sector as a whole - 22.6\%), of which $10.6 \%$ - for the use of e-mail; $9.3 \%$ - for hosting databases, file storage, $7.8 \%$ - for access to software provided by the provider, and only $3.5 \%$ - for hosting their own software (HSE 2019). The industry holds a similar position in terms of the share of organizations using electronic data exchange technologies between internal and external information systems; electronic purchases and sales; using software to provide access to databases through global information networks; as well as the cost of acquiring software, which comes to $3 \%$ of total in business sector (Table 1).

Nevertheless, in several indicators, mineral extraction organizations in Russia are superior to the average indicators for the business sector; for example, in the use of information protection tools and software to control automated equipment, processes, and factories (Table 1). The emphasis put by mining industry on these applications of digital technologies, from our point of view, can be explained by capital intensive and continuous character of production processes, on the one hand. On the other hand, due to uncertainty arising from the nature of mineral assets and enhanced by systematic and market risks, the quality of engineering design and operational efficiency are still the prior goals of mining companies.

\subsection{Economic and social issues}

It is worth noting that the average situation of Russian mining companies which are passing through the initial stage of digital transformation of business is also typical for foreign mining enterprises. Researchers see reasons for this in the management's underestimation of the digital transformation importance to business, in the age structure of the staff and a fairly high share of contracted workers in the industry (the global average is about a third), which together prevent the industry from quickly adapting to technological changes (Young \& Rogers, 2019). Russian companies are also experiencing problems due to the lack of incentives for digital transformation of business among management, staff resistance to ongoing changes and insufficient level of its digital culture, as well as a shortage of specialists with the necessary skills to work with modern digital technologies (KPMG, 2019). Even for such an indicator as the use of commercial Internet by organizations employees, Russia lags significantly behind European countries: $29 \%$ of the total number versus $75 \%$ in Sweden, $73 \%$ in Denmark, $70 \%$ in

Table 1. Comparative indicators of digital technologies use, as a percentage of the total number of organizations in the industry/business sector (2017).

\begin{tabular}{lll}
\hline Indicator & Mining industry, \% & Business average, $\%$ \\
\hline $\begin{array}{l}\text { The use of electronic data exchange technologies between } \\
\text { internal and external information systems }\end{array}$ & 59.4 & 62.2 \\
$\begin{array}{l}\text { Electronic procurement/sales } \\
\text { Software application: }\end{array}$ & $14.7 / 6.9$ & $18.5 / 12.3$ \\
- for access to databases through global information & 24.0 & 27.5 \\
networks & & 53.7 \\
- for financial evaluation in electronic form & 55.6 & 20.1 \\
- for managing automated production and (or) individual & 38.1 & 17.0 \\
technical equipment and technological processes & & 52.7 \\
- for engineering design & 29.9 & 64.8 \\
- for solving organizational, managerial and economic & 58.7 & \\
problems & & \\
$\begin{array}{l}\text { Application of software, hardware in order to prevent the } \\
\text { unauthorized access of malware }\end{array}$ & 77.0 & 61.4 \\
$\begin{array}{l}\text { Strong authentication } \\
\text { Application of software for automation processes of ana- } \\
\text { lysis and security computer systems control }\end{array}$ & 40.5 & 34.9 \\
$\begin{array}{l}\text { Biometric user authentication } \\
\text { The cost of acquiring software, million rubles }\end{array}$ & 7.5 & 5.7 \\
\hline
\end{tabular}

Source: Compiled by authors on the basis of HSE, 2019 Digital Economy Indicators 
Finland (HSE 2019). The social aspect is compounded by financial and economic barriers the lack of ability to finance digitalization projects in their businesses and doubts about the commercial feasibility of such projects.

International comparisons allow us to conclude that there are significant differences in the level of investment in European countries and the United States. For example, USA invest nearly 17.5 billion Euros per year in digital innovations, European countries - 3.5 billon Euros approximately (Bloching et al. 2015). The estimated Russian investments in digital transformation are almost three times lower than European and almost 15 times less compared to American ones. The cost of research and development in the Russian Federation in the direction of Information and Telecommunication Systems in 2017 amounted to 81.390 billion rubles, $61.4 \%$ of which was budget funds of all levels, and the own funds of companies and organizations amounted to only 15.6\% (HSE 2019). Such a cautious attitude of the mining business to digital projects is due to a combination of internal (managerial, technical and economic) and external (market, technical and institutional) barriers. Among them, especially following ones should be noted: the insufficient level of Russian integrated digital solutions supply for mining with high dependence on foreign technologies and equipment supplies; the lack of regulation of the digitalization process as well as a single digital platform for informing and interacting with parties interested in research and digital technology development (Lebedeva 2019).

European countries put a special emphasis on creating a balanced regulating framework which enables industry and governments to keep in pace with the dynamic digital transformation. Such a framework comprises conditions necessary for pan-European digital market functioning; revision of legal framework regulating data protection and issues, which are subjects to antitrust law; guaranteed high-quality network connections (Bloching et al. 2015).

\subsection{Legal aspects of digital data handling, ownership and intellectual property protection}

The large-scale use of digital technologies in the production and financial activities of mining companies will inevitably lead to the need to resolve a number of legal issues that concern the protection of the interests of mining companies when transferring information to third parties and using digital data structured in a certain way and unprocessed. The implementation of complex digital solutions in production and business processes is impossible without the open interaction of at least three parties - the company developing the digital solution, the company user of the solution and the company providing the development and creation of the necessary infrastructure - at the level of sharing machine data, structuring it and the creation of databases, the development of organizational, technical and information solutions that meet the specific needs and requirements of subsoil users, as well as the creation of digital ecobusiness systems. Such a diverse interaction creates the need to harmonize the economic interests of the parties in relation to the results obtained.

According to the standards of Russian law, the results of intellectual activity and equivalent means of individualization are subject to legal protection and are intellectual property (Civil Code of the Russian Federation, Article 1225). Being objects of civil rights, the results of intellectual activity themselves cannot be transferred (alienated) by one person to another, but the rights to such results and the tangible media in which they are expressed can be transferred from one person to another or alienated on the basis of license agreements and an agreement on the alienation of exclusive rights (the provisions of Section II of the Civil Code of the Russian Federation "Property Law and Other Property Rights" do not apply to intellectual rights).

State regulation envelopes issues related to intellectual property, computer programs (protected copyright objects, equivalent to literary works), databases (including those made upon fulfillment of contracts for research, development or technological work) and uniform technologies (created at the cost of or with the involvement of the federal budget of the Russian Federation or subjects of the Russian Federation). However, "ideas, concepts, principles, methods, processes, systems, means, solutions to technical, organizational or other problems, discoveries, facts, programming languages, geological information about subsurface resources" 
do not extend copyrights and, accordingly, legal protection (Civil Code of the Russian Federation, Article 1259). Among not regulated by the Civil Code of the Russian Federation are the collection, processing, transmission and other use of unstructured data that are not personal.

The question arises both of the legal status of the raw data, the systematization and further use of which will allow the company to derive economic benefits in the form of added value, savings on the amount of current costs, prevention of damage, reduction of capital costs and optimization of design decisions, and their economic content - determination of value for the purpose of acquisition (or, conversely, transfer) to third parties.

Legal regulation of the process of digital transformation of industry as a whole does not have time to follow the speed of technical and technological innovations, and this state of affairs is common not only for the Russian economy, but also of European countries where the legal status of digital data is also not defined, and «...the applicable national and international legal systems recognize neither ownership of data nor right of disposal over data ownership" (Paschke 2019). However, foreign companies have gained some practice in solving this problem - they provide legal protection of machine data through contractual agreements and factual control over such data (Paschke 2019).

\section{DISCUSSION}

The comparative analysis performed in the work, albeit indirectly (we admit that by the share of companies using certain digital solutions, it is impossible to draw full conclusions about the scale and depth of the transformation taking place in the industry), but reflects the presence of factors that impede the more intensive use by Russian mining companies digital technology. Industry specifics (the risky and inertial nature of the activity due to the capital intensity of production, the long lead time of projects, exposure to market fluctuations) are reinforced by institutional factors. At the government level, work is just beginning to create conditions for the development of the digital economy - a legal framework is being formed, infrastructure projects are being launched, and the need for training specialists with qualitatively new knowledge and skills is being recognized.

Even the current legal regulations already allow the mining industry the extensive digitalization of corporate communications and technical control processes. The legal regulations do not represent an obstacle but are open to the digitization of the industry in general and the mining industry in particular. The possibility of concluding contracts by digital means and the introduction of block chain technology, which could take place without changes in the law, are only exemplary but impressive proof of this. In the mining industry, too, the existing regulatory leeway can already be used to get the advantages of speed, reliability and ubiquitous availability of digital technology in the mining industry itself, in internal company communication, in communication with companies in the supply and sales chain and with government agencies.

Representatives of mining companies (usually large ones) have an interest in transforming businesses based on digital technologies, but today there is no confidence in the commercial feasibility of implementing such projects, since it is not always possible to evaluate them based on classical approaches and investment analysis methods. In this regard, the role of cooperation between universities (the scientific community), mining companies and companies developing digital business solutions is growing (Kazanin et al. 2017, Zhukovskiy et al. 2019b). Only in the process of coordinated interaction can one identify, explain, systematize and link the benefits of introducing digital technologies into mining business processes; offer a reasonable approach to the evaluation of digital projects and, finally, train specialists with the knowledge and skills that are in demand in the industry.

\section{CONCLUSION}

Answering the research question on the position of Russian mining companies in successful application of digital technologies, it was revealed that they are lagging behind other sectors 
of the economy (information technology, media, finance, insurance and manufacturing) in the scale and pace of the digital transformation of business processes.

Some barriers of economic and legal nature impede these processes. On the one hand, at the level of companies, there is not always a clear understanding of the potential and benefits of using digital technologies. Even oil and gas companies, being the leaders within extractive sector by adoption degree of digital technologies, struggle difficulties in scaling the digital initiatives (Accenture, 2019).

On the other hand, there is no comprehensive information about exactly what kind of solutions the mining business really needs and what domestic and foreign technology developers can offer. The creation of an integrated platform for the exchange of information on those technologies that are in demand by the Russian mining industry and can be offered by IT companies, would reduce the gap. The cooperation of mining, engineering and IT companies is of crucial importance to the process of digital transformation.

Another aspect influencing the process concerns the legal framework. The review of current laws and standards which are lagging behind technological progress and rapid development of information use underpins comprehensive application of digital technologies in mining.

\section{FUTURE RESEARCH AND ACKNOWLEDGEMENTS}

This research has been conducted under agenda of the Digitalization Work Group of Russian-German Raw Material Conference (27-29/11/2019). The Work group deals with the effects, opportunities and possibilities for cooperation in the digitization of the raw materials industry along the entire value chain. Authors would like to thank all participants of work group for a very fruitful meeting. This article is setting up a legal and economic scene for future research and cooperation endeavors in the Group, which will try to diversify its attention between a very wide range of problems encountered in digitalization of mining industry.

Regarding other aspects of digitalization in mining industry authors are inclined to highlight an educational side of this process. As was shown in literature review, there are three main directions for it - influence of technically enhanced learning on traditional education process; evaluation of already implemented digital technologies effectiveness; possible digital solutions of practical issues in mining industry education. In Saint Petersburg Mining University there are a number of possibilities regarding implementation of augmented and virtual reality projects (open pit mining training simulations, subsea oil and gas extraction visualization) in education. It is possible to evaluate these projects based on students and specialists' feedback and to appraise economic effect of advanced training cost cuts for enterprises because of higher level of students' skills.

\section{REFERENCES}

Abdelrazeq A., Daling L., Suppes R., Feldmann Y., Hees F. (2019) A virtual reality educational tool in the context of mining engineering - the virtual reality mine, Inted2019 Proceedings, pp. 8067-8073.

Accenture Oil and Gas Digital Trends Survey (2019). Access mode: https://www.accenture.com/fi-en/ insights/energy/trends-digital-investment. Access date: 06.04.2020.

Ajak, A.D., Lilford E., Topal, E. (2018) Application of predictive data mining to create mine plan flexibility in the face of geological uncertainty. Resources Policy. 55: 62-79. https://doi.org/10.1016/j. resourpol.2017.10.016.

Bag, S., Wood C. Wood, Xu L., Dhamija, P., Kayikci, Y. (2019) Big data analytics as an operational excellence approach to enhance sustainable supply chain performance. Resources, Conservation \& Recycling. 153, 104559. https://doi.org/10.1016/j.resconrec.2019.104559.

Barnelwold, L. (2019) Digital technology trends and their implementation in the mining industry. Mining Goes Digital - Mueller et al. (Eds). Taylor\&Francis Group, London. pp. 9-16.

Bergdahl, N., Nouri, J. \& Fors, U. (2020). Disengagement, engagement and digital skills in technology-enhanced learning. Educ Inf Technol 25: 957-983. https://doi.org/10.1007/s10639-01909998-w. 
Bhuiya, S. (2019) IoT applications in the mining industry. International Journal of Innovations in Engineering and Technology (IJIET). 12(3): 8-13. http://dx.doi.org/10.21172/ijiet.123.02.

Blaj-Ward, L., \& Winter, K. (2019). Engaging students as digital citizens. Higher Education Research and Development, 38(5), 879-892. doi:10.1080/07294360.2019.1607829.

Bloching, Björn \& Leutiger, Philipp \& Oltmanns, Torsten \& Rossbach, Carsten \& Schlick, Thomas \& Remane, Gerrit \& Quick, Paul \& Shafranyuk, Oksana. (2015). The digital transformation of industry - How important is it? Who are the winners? What must be done? Access mode: https://www.research gate.net/publication/304525645_The_digital_transformation_of_industry_-_How_important_is_it_ Who_are_the_winners_What_must_be_done Access date: 06.04.2020.

Bond, M., Marín, V.I., Dolch, C. et al. (2018). Digital transformation in German higher education: student and teacher perceptions and usage of digital media. Int J Educ Technol High Educ 15, 48 https:// doi.org/10.1186/s41239-018-0130-1.

Castañeda, L., Selwyn, N. (2018). More than tools? Making sense of the ongoing digitizations of higher education. Int J Educ Technol High Educ 15, 22. https://doi.org/10.1186/s41239-018-0109-y.

Civil Code of the Russian Federation. (2020). Access mode: Consultant+ database (in Russian).

Cui, Y., Kara, S., Chan, Ka C. (2020) Manufacturing big data ecosystem: a systematic literature review. Robotics and Computer Integrated Manufacturing. 62, 101861. https://doi.org/10.1016/j.rcim.2019.101861.

Digital technologies in Russian companies. Results of KPMG research. January 2019. Access mode: https://home.kpmg/ru/ru/home/insights/2019/01/digital-technologies-in-russian-companies-survey.html Access date: 06.04.2020.

Digital Transformation Index II. Dell Technologies. Access mode: https://www.delltechnologies.com/enus/perspectives/digital-transformation-index.htm Access date: 06.04.2020.

Digital twins for IoT applications (2017). Oracle white paper. Retrieved from http://www.oracle.com/us/ solutions/internetofthings/digital-twins-for-iot-apps-wp-3491953.pdf Access date: 06.04.2020.

Fourie Willem A.S. The digital mine eco-system. In: Mining Goes Digital: Proceedings of the 39th International Symposium "Application of Computers and Operations Research in the Mineral Industry" (APCOM 2019). Mueller et al. (Eds). pp. 491-496.

Gackowiec, P., Podobinska-Staniec M. (2019) IoT platforms for mining industry: an overview. Journal of the Polish Mineral Engineering Society. pp.267-272. http://doi.org/10.29227/IM-2019-01-47.

Global Cybersecurity Index (2018). ITU. Access mode: https://www.itu.int/pub/D-STR-GCI.01 Access date: 06.04.2020.

Henderson, M., Selwyn, N., \& Aston, R. (2017). What works and why? student perceptions of 'useful' digital technology in university teaching and learning. Studies in Higher Education, 42(8): 1567-1579. doi:10.1080/03075079.2015.1007946.

ICT Development Index 2017. Retrieved from: https://www.itu.int/net4/ITU-D/idi/2017/index.html\#i di2017rank-tab.

Indicators of digital economy (2019). Higher school of economics. https://www.hse.ru/primarydata/ ice2019 Access date: 06.04.2020.

Jiewu L., Qiang L., Shide Y., Jianbo J., Yan W., Chaoyang Z., Ding Z. (2019) Digital twin-driven rapid reconfiguration of the automated manufacturing system via an open architecture model. Robotics and Computer Integrated Manufacturing. 63, 101895. https://doi.org/10.1016/j.rcim.2019.101895.

Kazanin O.I., Sergeev I.B. (2017). Training a modern mining engineer: Objectives of universities and professional communities. Gornyi Zhurnal, 10, 75-80.

Kretschmann J., Plien M., Nguyen T.H.N., Rudakov M. (2020). Effective capacity building by empowerment teaching in the field of occupational safety and health management in mining. Journal of Mining Institute, 242, 248-256. DOI: 10.31897/PMI.2020.2.248.

Lee J., Cameron I., Hassal M. (2019). Improving process safety: what roles for digitalization and Industry 4.0? Process Safety and Environmental Protection. 132: 325-339. https//:doi.org/10.1016/j. psep.2019.10.021.

Litvinenko V.S., Sergeev I.B. (2019) Innovations as a factor in the development of the natural resources sector. Stud. Russ. Econ. Dev., 30, 637-645. https://doi.org/10.1134/S107570071906011X.

Magana A.J. (2017). Modeling and Simulation in Engineering Education: A Learning Progression. Journal of Professional Issues in Engineering Education and Practice. 143(4). DOI: 10.1061/(ASCE)EI.19435541.0000338.

Paschke M. (2019). Legal issues of the use of digital technology in mining - data ownership and liability. Scientific and Practical Studies of Raw Material Issues - Litvinenko (Ed.), 2020 Taylor \& Francis Group, London. P. 213-218.

Selwyn N., Hillman T., Eynon R., Ferreira G., Knox J., Macgilchrist F. \& Sancho-Gil J. M. (2020) What's next for Ed-Tech? Critical hopes and concerns for the 2020s, Learning, Media and Technology, 45(1): 1-6, DOI: 10.1080/17439884.2020.1694945. 
Stepanov I. Digitalization of coal and metal/Kommersant, "Mining. Metallurgy. Generation". Appendix \#174 25.09.2019, p. 9. Access mode: https://www.kommersant.ru/doc/4103010. Access date: 06.04.2020.

UN E-Government Survey 2018. Retrieved from: https://publicadministration.un.org/en/Research/UNe-Government-Surveys.

Wright, F., White, D., Hirst, T., \& Cann, A. (2014). Visitors and residents: Mapping student attitudes to academic use of social networks. Learning, Media and Technology, 39(1), 126-141. doi:10.1080/ 17439884.2013.777077.

Young A., Rogers, P. (2019) A review of digital transformation in mining. Mining, Metallurgy \& Exploration. 36: 683-699. https://doi.org/10.1007/s42461-019-00103-w.

Zhukovskiy Y., Batueva D., Buldysko A., \& Shabalov M. (2019a). Motivation towards energy saving by means of IoT personal energy manager platform. Journal of Physics: Conference Series, 1333, 062033. doi:10.1088/1742-6596/1333/6/062033.

Zhukovskiy Y.L., Koteleva N.I., Kovalchuk M.S. (2019b) Development of course feedback questionnaires of continuing professional education in the mining industry. Innovation-Based Development of the Mineral Resources Sector: Challenges and Prospects - 11th conference of the Russian-German Raw Materials, 589-597. 